\title{
Research misconduct and publication ethics: a South African perspective*
}

SADJ February 2019, Vol. 74 No. 1 p24 - p31

R Ballyram ${ }^{1}$, A Nienaber ${ }^{2}$

\section{SUMMARY}

Research misconduct is a global problem that tarnishes the reputation of researchers and research institutions and inevitably compromises the independence, integrity and credibility of the scientific record. Biomedical researchers, like all other professionals, are susceptible to pressures and temptations, which may result in their engaging in questionable research practices or even deliberate misconduct.

Preventing research misconduct is the first step in preserving and restoring the integrity of the scientific record. Understanding the causes of and the contributing factors associated with research misconduct is essential when devising preventative strategies. With reports of misconduct on the increase in South Africa and elsewhere, there is clearly a need to better equip researchers with the knowledge they need to conduct responsible, ethical research and to bring to their attention the most common forms of research misconduct (be it intentional or not) that are plaguing the scientific community.

\section{INTRODUCTION}

Over the past twenty-odd years, South Africa has witnessed a substantial growth in the number of scientific research studies conducted here, as well as the number of publications that flow from these studies, evidenced by the fact that in 2010 the country was ranked $33^{\text {rd }}$ in the world in terms of the number of research publications produced by South African scientists, the highest ranking yet achieved. ${ }^{1}$ This increase has been influenced strongly by the establishment of the NRF in 1999, an initiative having the objective to support and promote research. ${ }^{2}$

Incentives that reward prolific researchers and the tertiary or other institutions to which they belong have similarly raised publication rates. The Department of Higher Education and Training awards subsidies for publications appearing in accredited South African journals, as well as international, ISI and IBSS-accredited journals, books and book chapters, further incentivising research outputs.

\section{Author affiliations:}

1. Raoul Ballyram: BDS, MDS, MPhil, PGDip, Department of Periodontology and Oral Medicine, Sefako Makgatho Health Sciences University, Pretoria, South Africa.

2. Annelize Nienaber: $B$ Hons, LLB, LLM, LLD, Department of Public Law, University of Pretoria, Pretoria, South Africa.

*This article is based on the Masters dissertation of the first author (MPhil (Medical Law and Ethics) University of Pretoria, 2016).

Corresponding author: Raoul Ballyram

Senior Lecturer, Department of Periodontology and Oral Medicine,

Sefako Makgatho Health Sciences University, Pretoria, South Africa,

0204. Tel: +27 (0)12 5213771 E-mail: raoul.ballyram@smu.ac.za

$\begin{array}{ll}\text { ACRONYMS } \\ \text { CADC: } & \begin{array}{l}\text { Complaints and Advisory } \\ \text { Disciplinary Committee }\end{array} \\ \text { COPE: } & \text { Committee on Publication Ethics } \\ \text { FFP: } & \text { Fabrication, Falsification, and Plagiarism } \\ \text { ICMJE: } & \begin{array}{l}\text { International Committee of Medical } \\ \text { Journal Editors }\end{array} \\ \text { NHREC: } & \text { South African National Health Research } \\ & \text { Ethics Council } \\ \text { ORI: } & \text { Office of Research Integrity } \\ \text { QRP: } & \text { Questionable Research Practices } \\ \text { RCR: } & \text { Responsible Conduct of Research } \\ \text { REC: } & \text { Research Ethics Committee } \\ \text { USPHS: } & \text { US Public Health Service } \\ \text { WAME: } & \text { World Association of Medical Editors }\end{array}$

As a result, academics and researchers at universities and other institutions are placed under immense pressure, and are often compelled to 'publish or perish' in order to establish themselves or to achieve promotion.

Against the background of this massive drive to increase output, researchers who lack the necessary skills and knowledge may end up facing moral and ethical challenges and, as a result, may even commit research misconduct.

Research misconduct is a global problem that tarnishes the reputation of researchers and research institutions, and inevitably compromises the independence, integrity and credibility of the scientific community. ${ }^{3}$ Studies on the prevalence of research misconduct in the developing world, particularly in Africa, are scarce. ${ }^{3,4}$ However, in a recent study conducted among researchers in Nigeria, $68.9 \%$ of the respondents admitted to having committed some form of scientific misconduct. ${ }^{5}$

In order to curb growing incidences of research misconduct, a culture of research integrity should be fostered in South Africa. In light of the need to better equip researchers with the knowledge they require to conduct responsible, ethical research and to bring to their attention the most common forms of research misconduct (be it intentional or not) that are plaguing the scientific community, this article examines forms of research misconduct and highlights ways of combating the practice.

\section{FORMS OF RESEARCH MISCONDUCT}

Core values such as accountability, honesty and trustworthiness are indispensable when conducting, writing up, and publishing research. Research integrity, therefore, does not only involve adhering to ethical rules and regulations. ${ }^{6}$ 
At the $2^{\text {nd }}$ World Conference on Research Integrity held in Singapore in 2010, the "Singapore Statement on Research Integrity" was adopted. The document was developed with the intention of challenging researchers, governments and organisations to develop more comprehensive codes, standards and policies that would promote research integrity both locally and globally. ${ }^{7}$

According to the Singapore Statement, the four basic principles fundamental to research integrity are: honesty in all aspects of research; accountability in the conduct of research; professional courtesy and fairness in working with others, and good stewardship of research on behalf of others. ${ }^{8}$

The document further highlights the fundamental professional responsibilities to which investigators should adhere when conducting and publishing research. Every researcher, both established and novice, should be familiar with the contents of the Singapore statement, as well as with other important guidelines and policies on good publication practice, as listed in Table 1.

Research behaviour may broadly be categorised as: deliberate misconduct, often defined as fabrication, falsification, and plagiarism (FFP); questionable research practices (QRP); and responsible conduct of research (RCR). ${ }^{9-12}$ All institutions and researchers should strive to meet $\mathrm{RCR}$ as the ideal standard of research, deliberate misconduct should be avoided at all costs and QRP refers to research practices that fall somewhere between the two extremes of FFP and RCR. ${ }^{10}$
Deliberate fabrication or falsification of data undoubtedly constitutes gross scientific misconduct. Plagiarism at a tertiary and post-graduate level is inexcusable, and every institution of higher learning must have in place strict policies on this problem.

Other than FFP, deliberate misconduct also includes: falsification of credentials; duplication of publications; inaccurate author representation; deviation from or failure to adhere to a proposed protocol without proper permission; deception when writing research protocols; deception in the implementation of research; conducting research without the clearance of a Research Ethics Committee (REC) or similar body; failure to obtain informed consent; breach of confidentiality; as well as any unjustifiable deviations from the accepted ethical standards of research. ${ }^{13,14}$

QRP is described as any activity that may be detrimental to the research process but does not directly damage the integrity of the research itself. ${ }^{10} \mathrm{QRP}$ includes but is not limited to: misrepresentation, i.e. publishing results of the same experiment in several partial papers, with the intention of increasing the number of publications; inaccuracy, i.e. improper use of statistics and data analysis, careless citational errors, as well as inadequate abstract or summary writing; and, lastly, conflicts of interest and bias, i.e. presenting evidence or making decisions that are not scholarly or scientifically justifiable. ${ }^{10}$ Honest error, honest difference in opinion, and errors in interpretation do not constitute research misconduct. ${ }^{14-16}$

\section{Table 1. Important Guidelines and Policies on Good Publication Practice}

Guideline/Policy

COPE Guidelines on good publication practice

COPE How to handle authorship disputes: a guide for new researchers

COPE Retraction Guidelines

Text Recycling Guidelines (biomedcentral.com)

COPE A Short Guide to Ethical Editing for

New Editors

COPE Ethical Guidelines for Peer Reviewers

COPE Principles of Transparency and Best Practice in Scholarly Publishing

COPE Various flowcharts and E-seminars on dealing with and handling suspected research and publication misconduct

International Society for Medical Publication Professionals: Good Publication Practice for Communicating Company- sponsored Medical Research: the GPP2 guidelines

International Society for Medical Publication Professionals: Good Publication Practice for Communicating Company-sponsored

Avoiding plagiarism, self-plagiarism, and other questionable writing practices: A guide to ethical writing by Miguel Roig. (Posted on the Office of Research Integrity website)

WAME Recommendations on Publication Ethics Policies for Medical Journals

ICMJE Recommendations for the Conduct, Reporting, Editing, and Publication of Scholarly Work in Medical Journals

The Office of Research Integrity Website:Various E-Seminars, online modules and guidelines relating to publication ethics and research misconduct

\begin{tabular}{|c|c|c|}
\hline $\begin{array}{l}\text { Version/Last } \\
\text { Updated }\end{array}$ & Available online at: & $\begin{array}{l}\text { Date last } \\
\text { accessed }\end{array}$ \\
\hline 1999 & http://publicationethics.org/files/u7141/1999pdf13.pdf & 29-08-2016 \\
\hline 2003 & http://publicationethics.org/files/2003pdf12_0.pdf & 29-08-2016 \\
\hline 2009 & $\begin{array}{l}\text { http://publicationethics.org/files/retraction\%20guide- } \\
\text { lines.pdf }\end{array}$ & 26-08-2016 \\
\hline 2016 & https://publicationethics.org/resources/guidelines & 06-03-2018 \\
\hline 2016 & https://publicationethics.org/resources/guidelines & 06-03-2018 \\
\hline 2017 & https://publicationethics.org/resources/guidelines & 06-03-2018 \\
\hline 2018 & https://publicationethics.org/resources/guidelines & 06-03-2018 \\
\hline $\mathrm{n} / \mathrm{a}$ & http://publicationethics.org/resources/guidelines & 29-08-2016 \\
\hline 2009 & http://www.bmj.com/content/339/bmj.b4330 & 29-08-2016 \\
\hline 2015 & http://annals.org/article. aspx?articleid=2424869 & 29-08-2016 \\
\hline 2015 & https://ori.hhs.gov/sites/default/files/plagiarism.pdf & 29-08-2016 \\
\hline 2016 & $\begin{array}{l}\text { http://www.wame.org/about/recommenda- } \\
\text { tions-on-publication-ethics-policies }\end{array}$ & 29-08-2016 \\
\hline 2017 & http://www.icmje.org/recommendations/ & 06-03-2018 \\
\hline 2016 & http://ori.hhs.gov/ & 29-08-2016 \\
\hline
\end{tabular}


The Committee on Publication Ethics (COPE) is an internationally renowned organization that provides resources to editors and publishers on all aspects of publication ethics. ${ }^{17}$ It is the opinion of the authors of this paper that every journal editor and researcher should familiarise themselves with COPE's code of conduct, and other resources available on their website.

\section{Fabrication and Falsification}

Fabrication is defined as the 'making up' or fabrication of data or results and recording or reporting these with the deliberate intention of deceiving the scientific community. ${ }^{16,18}$ Fabricated data may be: used in the publishing of papers in scientific journals; presented at local and international scientific gatherings or conferences; used to fraudulently obtain research grants or patents. ${ }^{6}$

Falsification includes fabrication, and refers to the intentional suppression, distortion or manipulation of true scientific findings obtained from experimental or observational research, without any sound scientific or statistical justification. 6,18,19

Other forms of fabrication and falsification include selective reporting of results; failing to report results or findings that conflict with current reports in the literature; and manipulating images with the intention of obscuring or eliminating crucial information. ${ }^{18-20}$

It goes without saying that the intentional publication of fabricated and falsified research undermines the reliability and the integrity of the research record. ${ }^{10}$

\section{Plagiarism}

There are many overlapping definitions of plagiarism in the literature. The most popular being that of the Office of Research Integrity (ORI). According to the ORI, plagiarism is "the appropriation of another person's ideas, processes, results, or words without giving appropriate credit". ${ }^{16}$

The authors of this paper suggest combining that definition with that of the World Association of Medical Editors (WAME), thus defining plagiarism as:

The use of another person's unpublished or published ideas, words, results, processes or any other intellectual property (including those obtained through confidential review of research proposals and manuscripts) without attribution or permission, and presenting them as your own, new or original. ${ }^{16,20}$

As per the definition proposed above, so-called 'borrowed' information is not limited to written texts (i.e. articles, books, dissertations, theses, etc.), but also includes other intellectual property, such as audio-visual presentations, multimedia and online sources, for instance, videos and websites, spoken text such as speeches and lectures, ideas, research manuscripts and methods, or any other privileged communication. . $^{61}$

Another hotly-contested topic of discussion falling under the ambit of FFP is self-plagiarism. Self-plagiarism is when an author republishes work in its entirety or reuses portions of previously-published work or data on the same topic in another publication, without specifically acknowledging it. ${ }^{20,22}$ Prima facie 'self-plagiarism' indeed is an oxymoron 'How can one steal from oneself?'. ${ }^{23,24}$

Nevertheless, there are complex variables at play in the arena of self-plagiarism, including copyright law; how much text re-use is permissible; when to cite; as well as the appropriate use of quotation marks. ${ }^{23}$

Self-plagiarism can be categorised broadly into: redundant or duplicate publications; 'double-dipping' or academic self-plagiarism; 'salami slicing'; and text recycling. ${ }^{10,24}$ An excellent article written by Roig ${ }^{24}$ highlights 28 comprehensive guidelines dealing with plagiarism, self-plagiarism and ethical scientific writing. Roig's paper is a must-read for every researcher - both novice and established.

Some of the guidelines relating to self-plagiarism discussed in the article include the following:

- Any manuscript being submitted for publication that has already been previously disseminated (i.e. as a published article in a journal, presentation at a conference or scientific meeting, or published on the internet) must inform both the editors and the readers of the previous dissemination. ${ }^{24}$

- Authors of single complex studies should as far as possible try to present data as a cohesive whole, instead of partitioning it into multiple separate papers. ${ }^{24}$

- Authors should familiarise themselves with the basics of copyright law, as extensive paraphrasing or quoting from a book may constitute copyright infringement. ${ }^{24}$

- Even though there are some instances where text recycling is permissible, authors should avoid reusing their own previously-published text, unless it is properly paraphrased, placed within quotation marks and, of course, correctly cited. ${ }^{24}$

Double-dipping or academic self-plagiarism occurs when an entire research report, dissertation or thesis (or a substantial part of this work) is submitted in order to fulfil a course or degree requirement, even though that work had been submitted previously to satisfy the requirements for another programme at a different university or academic institution. ${ }^{24}$

Plagiarism may not have a significant impact on the reliability of the research record (provided that the original work being plagiarised is scientifically accurate). ${ }^{10}$ It does, however, result in funds being wasted for review of the publishing of plagiarised work; furthermore, it undermines trust and collegiality within the scientific community. ${ }^{10}$

There are various software packages on the market that are able to detect plagiarism, such as Turnitin $\AA^{26}$ and PlagScan ${ }^{2}{ }^{27}$ Such programmes are used routinely by institutions of higher learning to check the originality of academic papers, dissertations and theses. As remarked previously, every academic institution must have a strict plagiarism policy in place, and every researcher affiliated with such institutions should be made aware of such policies. 


\section{Inappropriate Authorship}

Biomedical issues are complex and often require the expertise of a research team. Furthermore, technological advances have allowed researchers from all over the world to collaborate. ${ }^{24}$ Such projects invariably result in multi-authored publications.

There is no universal definition for 'authorship', however, according to the WAME, in order for a researcher to qualify for authorship he/she should make a significant intellectual contribution to a study (i.e. contribute to writing the manuscript, as well as reviewing the final draft). ${ }^{20}$

Questions regarding authorship that often arise include: Who should be an author, and in what sequence? Should people in power such as heads of departments receive automatic authorship? Who should receive acknowledgement? Such matters should be resolved early on in the research process, so as to avoid any disputes which may delay the publishing of a paper. ${ }^{20} \mathrm{~A}$ number of professional societies, and many scientific journals, have published guidelines relating to authorship.

The guidelines published by the International Committee of Medical Journal Editors (ICMJE) are by far the most popular, and have been adopted by more than 3000 scientific journals worldwide.

According to the ICMJE, an individual only qualifies for authorship if he/she satisfies all of the following four criteria:

1. "Substantial contributions to the conception or design of the work; or the acquisition, analysis, or interpretation of data for the work; and

2. Drafting the work or revising it critically for important intellectual content; and

3. Final approval of the version to be published; and

4. Agreement to be accountable for all aspects of the work in ensuring that questions related to the accuracy or integrity of any part of the work are appropriately investigated and resolved". ${ }^{28}$

Furthermore, the main author should be able to identify which co-authors are responsible for different parts of the work. ${ }^{28}$ Individuals who do not meet all of the criteria mentioned above should not be listed as authors, but rather their contributions acknowledged. ${ }^{28}$ Other individuals who may be acknowledged include those involved in: data collection; scientific advisory; critical review of the proposal, as well as in technical editing, language editing, and proof-reading of the manuscript. ${ }^{28}$

Other popular terms coined under the ambit of inappropriate authorship include, 'Ghost Authorship' and 'Honorary' or 'Gift' authorship. Honorary or gift authorship basically entails including as an author an individual who does not meet the authorship criteria highlighted above.

This practice is common in academe, where junior staff members are coerced into including heads of departments and senior staff members as co-authors in their publications. The pressures of publishing, getting funding, promotions and gaining respect from peers, further exacerbate this practice..$^{29,30}$
A ghost author is an individual who has made a substantial contribution to a work, but who is not named as an author. ${ }^{31}$ This practice has become increasingly popular in the pharmaceutical and biomedical industry. Medical writers are paid large sums of money to write articles detailing results of clinical drug trials, and are not credited with authorship or acknowledgement. ${ }^{6}$

The idea is that these 'ghost' writers are paid by such companies in order to ensure these articles are written in a way that portrays their product in a favourable light. ${ }^{32}$ Well-known and respected academics and expert researchers in the field are then recruited to write a 'balanced' review of the product. ${ }^{24}$ These researchers, however, are furnished with a draft paper (already written to specification by the ghost author) in order to facilitate the write-up. ${ }^{32,24}$ Using the names of well-known expert researchers improves the 'credibility' of these papers, thus streamlining peer-review and publication. ${ }^{32}$

In order to preserve the credibility and accountability of the scientific record, researchers, research and academic institutes as well as scientific journals must encourage authors to adhere to currently-accepted criteria for authorship.

\section{Conflicts of interest and Bias}

A conflict of interest arises when an individual's relationship to an organization/industry or other party has the potential to compromise or to bias professional judgement or objectivity in the conduct of scholarly or scientific research. ${ }^{24,29}$ This relationship need not necessarily be a personal or financial one. ${ }^{24}$ Furthermore, a conflict of interest need only imply the potential for bias, not necessarily a likelihood. ${ }^{29}$ According to Steneck ${ }^{10}$, bias means "making decisions or presenting evidence for other than scientific or scholarly reasons"10. The basis of scientific research is objectivity, and once objectivity is influenced by bias, research is compromised.

Conflicts of interest may be categorised broadly as either tangible or intangible. ${ }^{29}$ Intangible conflicts of interest are often overlooked and include, among others: conflicts of interest at an individual level; intellectual bias and conflicts of conscience. ${ }^{29}$ Conflicts of interest at an individual level relate to the pressures of publishing, getting funding, academic promotions and earning the respect of peers. ${ }^{29,30}$ Such pressures may lead to diminished objectivity, which may result in bias. ${ }^{29}$ Intellectual bias includes but is not limited to unethical peer-review, which will be discussed further in this paper. ${ }^{29}$ Conflicts of conscience occur when a personal belief influences objectivity in research; for example, personal or religious views may cloud a researcher's objectivity on a study involving embryonic stem cell research. ${ }^{29}$

Tangible or measurable conflicts of interest usually involve financial gain or benefit. ${ }^{29}$ Financial conflict of interest and its effect on academe are aptly summarised in this statement by Johnston: ${ }^{33}$

"Traditionally, academic biomedical research institutions and for-profit companies have had different missions. Academic institutions have focused on teaching, research, and public service, whereas companies have 
focused on generating revenue through commercial activities. But the distinction between their missions is becoming blurred now that academic institutions and their employees have opportunities to make significant amounts of money - from research contracts, equity holdings, patents, and other relationships with industry..." ${ }^{33}$

Such conflicts of interest may compromise the quality of biomedical research, which may, in turn, result in harming research subjects, patients or anyone who relies on such research. ${ }^{33}$ Several American professional societies and scientific journals have adopted a 'zero tolerance' policy when dealing with financial conflicts of interest. ${ }^{29,34}$

Non-financial conflicts of interest include any relationship that could inappropriately influence or have the potential to influence professional judgment, such as personal relationships (i.e. close personal friends or immediate family members). Conflicts of interest, however, are not only limited to researchers. Journal editors as well as peer reviewers also need to disclose relevant conflicts of interest and, if need be, withdraw from the review and selection process if there is potential for bias. ${ }^{28}$

Now that we have outlined the different forms that research misconduct may take, we turn to ways in which the scientific community may combat research misconduct.

\section{COMBATING RESEARCH MISCONDUCT}

\section{Ethical Peer-review}

The peer-review process is considered to be the benchmark of the scientific publication process and is critical in ensuring the dissemination of sound scientific knowledge (i.e. it allows for a fair hearing of a manuscript among peers in the scientific community). ${ }^{24,29}$ It is unethical to allow a flawed paper devoid of any scientific merit to pass unchallenged into the peer-reviewed literature. ${ }^{34}$

Peer-reviewers usually are experts on a particular scientific topic, and are required to have at least: a history of having conducted and published original research; formal training in the relevant science; as well as experience in critically appraising manuscripts. ${ }^{24}$

The following guiding ethical principles should be adhered to during the peer-review process:

- Manuscripts submitted to journals prior to publication are privileged communications and are the intellectual property of the authors. Both editors and peer-reviewers must, therefore, treat manuscripts as confidential documents. ${ }^{24,28,34}$ Peer-reviewers are not allowed to cite or use any data from a manuscript that they have reviewed, before it is officially published. ${ }^{35}$

Moreover, peer-reviewers should keep the outcome of their reviews confidential, and manuscripts should not be discussed with colleagues. ${ }^{24}$ If a manuscript is rejected, it is best practice for journals and peerreviewers to delete all copies of it from their editorial systems, unless otherwise required by regulations. ${ }^{28}$
Peer-reviewers should provide objective, unbiased, timely, accurate, clear, concise, justifiable and constructively critical reports. Furthermore, reviewers should uphold the precepts of collegiality and refrain from making rude, snide, sarcastic and argumentative remarks when writing reviews. ${ }^{34,36}$

- Journals have different policies regarding whether the review process is open or blinded, generally the identity of the reviewers are known to the editor, but this information is not released to the authors, to fellow reviewers, or third parties. ${ }^{34}$ This anonymity allows reviewers to provide a critical and honest review without the risk of victimisation from their peers. ${ }^{34}$

- Timeliness is extremely important in the peer-review process. Journals require reviewers to review a manuscript within a specific time-frame. It is unfair to the author and to the journal to accept a paper for review if it cannot be reviewed within the specified time-frame, as there always is the risk of the manuscript becoming outdated. Furthermore, it is unethical to rush a review; to perform careless and superficial reviews; or to review a manuscript if one does not possess the necessary subject expertise required to do so. ${ }^{36}$

- When reviewing a manuscript the following factors should be considered: the suitability for publication in the journal; the importance and novelty of the science; the appropriateness of the research design; the quality and validity of the data; the interpretation of the data; appropriate statistical analysis; as well as the reliability and validity of the conclusions drawn from the study. ${ }^{34}$

Editors and reviewers should not exclude from consideration credible studies with inconclusive findings or credible studies that challenge the existing dogma. ${ }^{28,34}$ The main aim of peer-review is to focus on the scientific credibility of the manuscript and not minor editorial problems, unless the grammar used renders the manuscript erroneous, unclear or ambiguous. ${ }^{34}$

- As alluded to earlier, peer-reviewers should declare all real and perceived conflicts of interest and recuse themselves from the peer-review process if they have a real or perceived conflict of interest that may compromise the objectivity of the review, or that may appear to compromise its objectivity. ${ }^{28,34,36}$

- Most journals have strict policies and ethical guidelines for studies conducted on human or animal subjects. Ensuring that a study complies with journal policies and institutional REC policies as well as national regulations and guidelines governing research on humans, is an important part of the peer review process. ${ }^{34}$

- Lastly, journals should publish accurate descriptions of their peer-review policies (i.e. reviewer selection, review completion times and appeals processes), as well as annual audits of acceptance rates, publication times, and other performance data..$^{35}$

An academic/intellectual conflict of interest occurs when a reviewer interferes with the peer-review process for some type of intangible personal gain. ${ }^{29}$ If the content of a 
manuscript is too closely related to the work of a reviewer (published or unpublished), then there is always a risk of bias. In such cases, it is best practice for a reviewer to contact the editor, and recuse him/herself from the review process.

If a reviewer suspects serious breaches in publication ethics and/or research misconduct, he/she should notify the editor in confidence. ${ }^{24}$ The editor should then decide whether an official investigation is warranted.

Until the investigation is finalised, both the editor and the reviewer should be thoughtful and extremely discreet in their discussions and deliberations as the consequences for authors, the journal and the scientific record could be calamitous. ${ }^{34}$

\section{Maintaining the integrity of the scientific literature}

The drive to publish or perish coupled with financial and professional incentives to conduct research, as well as the media's recent portrayal of the dangers associated with biomedical research, against the backdrop of an increase in the number of reported cases of research misconduct have led to increased public and regulatory scrutiny of biomedical research.

This concern is not unwarranted as there is consensus in the scientific community that the number of reported cases of research misconduct, as well as the number of journal retractions is unacceptably high.

The first step in repairing and maintaining the integrity of the scientific literature would be to preserve and restore the quality of biomedical research. The scientific literature is only as reliable as the trustworthiness and calibre of the research team, therefore, the development and training of ethical, adequately-qualified researchers is crucial in fighting the battle against scientific misconduct.

At the request of the United States' Office of Research Integrity, the Institute of Medicine in collaboration with the National Research Council's Division on Earth and Life Studies formed the Committee on Assessing Integrity in Research Environments in 2001, which has proposed recommendations to improve research Integrity. Some of these are listed below:

- Funding agencies should establish research grants dedicated to funding future research aimed at investigating factors that influence integrity in research. ${ }^{37}$

- Research institutions should develop and implement comprehensive programmes designed to promote integrity in research, such as educational short courses aimed at enhancing responsible conduct of research. ${ }^{37}$

- The integrity of these research environments should be evaluated and enhanced through a process of continuous self-assessment and external peer review. ${ }^{37}$

Nevertheless, it is unreasonable to expect the research process to be completely error-free. How does one manage a situation where a fraudulent or inaccurate study manages to slip through the cracks in the system and is published in the scientific literature? According to the COPE, journal editors should consider retracting a publication if:

- There is clear evidence that the findings are unreliable, either as a result of deliberate misconduct or honest error. ${ }^{38}$

- The findings have been published previously (without proper cross-referencing, permission or justification). ${ }^{38}$

- There is evidence of plagiarism. ${ }^{38}$

- There is evidence of unethical research. ${ }^{38}$

Journal editors may issue an expression of concern if:

- There is inconclusive evidence of research or publication misconduct. ${ }^{38}$

- There is evidence that the findings of a study are unreliable but the affiliated institution will not conduct an investigation. ${ }^{38}$

- There is reason to believe that an investigation into alleged misconduct related to the publication either has not been, or would not be, impartial, fair or conclusive. ${ }^{38}$

- An investigation is underway, but there will be a considerable amount of time before the outcome will be made available. $^{38}$

Journal editors should issue a correction if:

- A small part of an otherwise reliable publication proves to be misleading, due to honest error. ${ }^{38}$

- If a deserving author has been omitted or somebody who does not meet authorship criteria has been included in the author list. ${ }^{38}$

Fraudulent publications should ideally be retracted by the author(s) themselves; however, editors may retract publications (or issue expressions of concern) if all or some of the authors refuse to cooperate. ${ }^{38}$

Furthermore, affiliated research institutions should take on the responsibility of carefully scrutinising all other publications by the guilty authors for possible misconduct. ${ }^{39}$

A published retraction notice should: be clearly identified as a retraction; clearly identify the title and authors of retracted article; be published as soon as possible; include the reasons for retraction (clearly distinguishing misconduct from honest error), ideally quoting the findings of the investigations; be linked to the retracted article wherever possible (i.e. in all electronic versions); be freely available to all readers; state who is retracting the article; and avoid statements that are potentially defamatory or offensive. 38,39

Retraction notices must also appear in all electronic sources such as the journal website; bibliographic databases and electronic search engines. ${ }^{38,39}$ Furthermore, it is imperative that journal editors make it mandatory for 
authors submitting papers to journals, to check that they have not cited any retracted articles in their reference lists. ${ }^{39}$

Scientists have a moral duty and a professional obligation to warn the scientific community of these tainted publications, so as to prevent contamination of the literature through inadvertent citation of such publications. ${ }^{39}$ With technological advances such as electronic journals readily accessible on the internet, scientific findings are globally disseminated. However, the regulation and enforcement of ethical research is local. ${ }^{39}$ Cleansing the medical literature of tainted publications is a complex task that requires a collective effort on the part of scientists, research institutes and government institutions.

\section{Managing allegations of research misconduct}

The United States was one of the first countries in the world to establish a government system for evaluating allegations of scientific fraud and misconduct. In March 1989, the US Congress established the Office of Scientific Integrity and in 1992 this office was consolidated into what is today known as the Office of Research Integrity (ORI). ${ }^{40}$

The ORI is considered to be an authority on promoting research integrity and managing research misconduct and many countries around the world, including South Africa, use their policies and guidelines as a benchmark.

Even though the ORI only deals with cases of misconduct relating to federally-funded research, its influence has extended informally to other research ${ }^{39}$, and many research and academic institutes both in the US and internationally have adopted the ORl's administrative procedures for handling research misconduct. Furthermore, many South African Universities are involved in collaborative research that is funded by the US Public Health Service (USPHS). These institutes are legally compelled to notify the ORI of any alleged research misconduct involving USPHS funds, and to develop and implement processes for responding to such allegations that are consistent with US Federal regulations. ${ }^{41}$ In compliance with section 72 of the National Health Act 61 of 2003, the South African National Health Research Ethics Council (NHREC) established the Complaints and Advisory Disciplinary Committee (CADC).

This committee is mandated to: adjudicate complaints about the functioning of RECs; to hear a complaint from a researcher who believes that a REC has discriminated unfairly against him; to refer matters involving allegations of violation of ethical or professional rules or standards by a health care provider to the relevant statutory health professional council or body; to institute remedial measures and disciplinary action where warranted, and to facilitate compliance with legal, ethical and professional norms and standards as required for responsible conduct of research. ${ }^{42}$

In South Africa, the regulatory framework for dealing with allegations of research misconduct starts at an institutional level through the RECs; followed by the NHREC and its CADC; thereafter the matter may be referred to statutory professional bodies and, lastly, if necessary legal processes may be instituted..$^{43}$
The CADC published a guideline for the management of complaints in 2012, and later updated it in 2015. The content of these guidelines is of vital importance as it outlines in detail the processes that should be followed by the CADC when dealing with complaints. All members of the scientific community in good standing are morally and professionally obliged to report suspected cases of misconduct to the relevant authorities. In the NHREC's Annual Reports for 2014/2015 and 2015/2016 it was reported that the CADC handled as few as seven complaints during the period. ${ }^{42,44}$ This implies that the bulk of research misconduct cases are resolved at an institutional level (by RECs) without the intervention of the CADC. The authors of this paper, however, are of the opinion that this figure is far too low, and we suspect that perhaps the existence, duties and functions of the CADC are not well publicised among the research community.

\section{CONCLUDING REMARKS}

Like other professionals, scientists are also susceptible to pressures and temptations ${ }^{45}$ which may result in their engaging in questionable research practices or deliberate misconduct.

Research misconduct is a very real problem plaguing the scientific community, and the damage that it inflicts on the integrity and credibility of the scientific record, and on public health and opinion, is detrimental and extremely difficult to remedy.

This article outlined a number of forms that research misconduct may take, and it highlighted strategies to fight this scourge, strategies which should be aimed at preventing misconduct, rather than at repairing the damage it inflicts. Our aim, therefore, is to expose the reader to current policiesiguidelines relating to the management of research misconduct, both globally and in South Africa.

By sensitising readers to the problem of research misconduct, and by highlighting current and future strategies which may be applied to fight this blight, we hope to have contributed in a small way to the preservation of the scientific record.

\section{References}

1. Pouris A. Science in South Africa: the dawn of a renaissance?: research article. S Afr J Sci. 2012;108(7):1-6.

2. Inglesi-Lotz R, Pouris A. Scientometric impact assessment of a research policy instrument: the case of rating researchers on scientific outputs in South Africa. Scientometrics 2011;88(3):747-60.

3. Okonta PI, Rossouw T. Misconduct in research: a descriptive survey of attitudes, perceptions and associated factors in a developing country. BMC Med Ethics. 2014;15:25.

4. Ana J, Koehlmoos T, Smith R, Yan LL. Research misconduct in low- and middle-income countries. PLoS Med.2013;10(3):1-5.

5. Okonta P, Rossouw T. Prevalence of scientific misconduct among a group of researchers in Nigeria. Developing World Bioethics 2013;13(3):149-57.

6. Coughlin SS, Barker A, Dawson A. Ethics and scientific integrity in public health, epidemiological and clinical research. Public Health Rev. 2012;34(1):71-83.

7. Singapore Statement on Research Integrity [Internet]. Singapore Statement on Research Integrity home page. World Conference on Research Integrity; [updated 2010/9/22; cited 2016 /8/08]. Available from: http://www.singaporestatement.org. 
8. Singapore Statement on Research Integrity. Presented at the $2^{\text {nd }}$ World Conference on Research Integrity; 2010 July 21-24; Singapore.

9. Mitcham C. Co-responsibility for research integrity. Sci Eng Ethics. 2003;9(2):273-90.

10. Steneck NH. Fostering integrity in research: Definitions, current knowledge, and future directions. Sci Eng Ethics. 2006;12(1):53-74.

11. Galland JC. Developing, Sharing and Promoting Best Practices. Presented at the $2^{\text {nd }}$ World Conference on Research Integrity; 2010 July 21-24; Singapore.

12. Steneck NH. The Responsible Conduct of Basic and Clinical Research. Presented at the International Bioethics Conference; 2005 June 3-4; Poland.

13. Dhai A. Preventing Research Misconduct: Some Programs in Africa. Presented at the $2^{\text {nd }}$ World Conference on Research Integrity; 2010 July 21-24; Singapore.

14. The Health Professions Council of South Africa [Internet]. Guidelines for Good Practice in the Health Care Professions: General Ethical Guidelines for Health Researchers. [updated 2008; cited 2016/1/12]. Available from: http://www.hpcsa. co.za/Uploads/editor/UserFiles/downloads/conduct_ethics/ rules/generic_ethical_rules/booklet_6_gen_ethical_guidelines_ for_researchers.pdf.

15. Bolton PA [Internet]. Scientific Ethics. Air University.[updated 2002; cited 2016/5/25]. Available from: http://www.au.af.mil/ au/awc/awcgate/doe/benchmark/ch16.pdf.

16. The Office of Research Integrity [Internet]. Definition of Research Misconduct. U.S. Department of Health and Human Services; [cited 2016/3/20]. Available from: https://ori.hhs.gov/ definition-misconduct.

17. Committee on Publication Ethics [Internet]. About Cope. [updated 2016; cited 2016/5/25]. Available from: https:// publicationethics.org/about.

18. Khanyile TD, Duma S, Fakude LP, Mbombo N, Daniels F, Sabone MS. Research integrity and misconduct: a clarification of the concepts. Curationis 2006;29(1):40-5.

19. Fanelli $D$. How many scientists fabricate and falsify research? A systematic review and meta-analysis of survey data. PloS One 2009;4(5):e5738.

20. World Association of Medical Editors [Internet]. Recommendations on Publication Ethics Policies for Medical Journals. [updated 2016; cited 2016/8/24]. Available from: http:// www.wame.org/about/recommendations-on-publicationethics-policie\#Plagiarism.

21. Moodley K. Research Ethics and Scientific Integrity. In: Moodley K, editor. Medical Ethics, Law and Human Rights: A South African Perspective. Pretoria: Van Schaik Publishers; 2011. pp 334

22. iThenticate [Internet]. White Paper The ethics of self plagiarism. iThenticate by Turnitin; [updated 2011; cited 2016/6/25] Available from: http://www.ithenticate.com/resources/papers/ ethics-of-self-plagiarism.

23. Woker T. Oops I said it again... self-plagiarism or text re-use: when or is it acceptable? Obiter 2011;32(2):233-48.

24. Roig M [Internet]. Avoiding plagiarism, self-plagiarism, and other questionable writing practices: A guide to ethical writing. U.S. Department of Health and Human Services; [updated 2015; cited 2016/8/29]. Available from: https://ori.hhs.gov/sites/ default/files/plagiarism.pdf.

25. Angell M, Relman AS. Redundant publication: Mass Medical Soc. 1989;320:1212-4.

26. Turnitin. 2101 Webster St., Suite 1800, Oakland, California 94612.

27. PlagScan - Gesellschaft mit beschränkter Haftung. Gruener, Weg 10, 50825 Cologne, Germany.

28. International Committee of Medical Journal Editors [Internet]. Recommendations for the Conduct, Reporting, Editing, and Publication of Scholarly Work in Medical Journals. [updated 2015;cited 2016/05/23]. Available from: http://www.icmje.org/ icmje-recommendations.pdf.

29. The Office of Research Integrity [Internet]. RCR Conflicts of
Interest Module (e-Seminar). U.S. Department of Health and Human Services; [Cited 2016/8/28] Available from:

30. https://ori.hhs.gov/education/products/columbia_wbt/ rcr_conflicts/foundation/index.html.

31. Korn D. Conflicts of interest in biomedical research. JAMA. 2000;284(17):2234-7.

32. Wislar JS, Flanagin A, Fontanarosa PB, DeAngelis CD. Honorary and ghost authorship in high impact biomedical journals: a cross sectional survey. BMJ. 2011;343:d6128.

33. Mercola.com [Internet]. How big Pharma fools even your doctor. Dr Joseph Mercola; [updated 2011/11/26; cited 2016/08/08] Available from: http://articles.mercola.com/sites/ articles/archive/2011/11/26/medical-journals-using-ghostwriters.aspx.

34. Johnston J. Conflict of Interest in Biomedical research in From Birth to Death and Bench to Clinic: The Hastings Center Bioethics Briefing Book for Journalists, Policymakers, and Campaigns. Garrison, NY: The Hastings Center; 2008.

35. Rockwell S [Internet]. Ethics of peer review: a guide for manuscript reviewers. Department of Therapeutic Radiology: Yale School of Medicine; [Cited 2016/08/28]. Available from: http://www.radonc.yale.edu/training/policies/Ethical_Issues_ in_Peer_Review_tcm307-34211_tcm307-284-32.pdf.

36. Committee on Publication Ethics [Internet]. Committee on Publication Ethics (COPE) Guidelines on Good Publication Practice. [updated 1999; cited 2016/6/07. Available from: http://publicationethics.org/files/u7141/1999pdf13.pdf.

37. Committee on Publication Ethics [Internet]. COPE Ethical Guidelines for Peer Reviewers. [updated 2013; cited 2016/8/25]. Available from: http://publicationethics.org/files/ Peer\%20review\%20guidelines_0.pdf.

38. National Research Council. Integrity in scientific research: Creating an environment that promotes responsible conduct. Washington, DC: National Academic Press 2002.127-32.

39. Committee on Publication Ethics [Internet]. Retraction Guidelines. [updated 2009; cited 2016/9/14]. Available from: http://publicationethics.org/files/retraction\%20guidelines.pdf.

40. Sox HC, Rennie D. Research misconduct, retraction, and cleansing the medical literature: lessons from the Poehlman case. Ann. Intern. Med. 2006;144(8):609-13.

41. The Office of Research Integrity [Internet]. Historical Background: The Beginning. Department of Health and Human Services; [cited 2016/3/20]. Available from: https://ori.hhs.gov/ historical-background.

42. UCT Research Support Hub [Internet]. Statement on Dealing with Allegations of Research Misconduct Under United States Public Health Service (USPHS) Research-related Activities for Foreign Institutions. Univeristy of Cape Town. [updated 2015; cited 2016/9/21]. Available from: http://www. researchoffice.uct.ac.za/usr/researchoffice/integrity/ori-foreign-statement_11-20-2015.pdf.

43. National Health Research Ethics Council [Internet]. National Health Research Ethics Committee Annual Report (2014-2015). Republic of South Africa: Department of Health [updated 2015; cited2016/6/07].Availablefrom:http://www.nhrec.org.za/index. php?option=com_phocadownload\&view=category\&id=6.

44. Dhai A. Best Practices For Ensuring Scientific Integrity and Preventing Misconduct - South African Processes and Procedures. Presented at The Organisation for Economic Co-operation and Development, Global Science Forum; 2007 February; Japan.

45. National Health Research Ethics Council [Internet]. National Health Research Ethics Committee Annual Report (20152016). [updated 2016; cited 2017/03/06. Available from: http://www.nhrec.org.za/index.php?option=com_phoca download\&view $=$ category\&id $=6$.

46. Organisation for Economic Co-operation and Development [Internet]. Organisation for Economic Co-Operation and Development Global Science Forum: Best Practices for Ensuring Scientific Integrity and Preventing Misconduct. [updated 2007; cited 2016/8/20]. Available from: https://www.oecd.org/sti/scitech/40188303.pdf. 